\title{
Direct Metal Deposition of H13 Tool Steel on Copper Alloy Substrate: Parametric Investigation
}

\author{
M. Khalid Imran ${ }^{1}$ • S. H. Masood ${ }^{1}$ - Milan Brandt ${ }^{2}$
}

Accepted: 2 October 2015 / Published online: 6 October 2015

(C) Springer Science+Business Media New York 2015

\begin{abstract}
Over the past decade, researchers have demonstrated interest in tribology and prototyping by the laser aided material deposition process. Laser aided direct metal deposition (DMD) enables the formation of a uniform clad by melting the powder to form desired component from metal powder materials. In this research $\mathrm{H} 13$ tool steel has been used to clad on a copper alloy substrate using DMD. The effects of laser parameters on the quality of DMD deposited clad have been investigated and acceptable processing parameters have been determined largely through trial-and-error approaches. The relationships between DMD process parameters and the product characteristics such as porosity, micro-cracks and microhardness have been analysed using scanning electron microscope (SEM), image analysis software (ImageJ) and microhardness tester. It has been found that DMD parameters such as laser power, powder mass flow rate, feed rate and focus size have an important role in clad quality and crack formation.
\end{abstract}

Keywords DMD parameters $\cdot$ Bi-metallic tooling $\cdot$ Microhardness $\cdot$ Porosity $\cdot$ Tool steel clad

\section{Introduction}

Die coatings and surface treatments are used to improve the properties of the dies for many applications. Physical vapor deposition (PVD), chemical vapor deposition

S. H. Masood

smasood@swin.edu.au

1 Faculty of Science Engineering and Technology, Swinburne University of Technology, Melbourne 3122, Australia

2 School of Aerospace, Mechanical and Manufacturing Engineering, RMIT University, Melbourne 3083, Australia 
(CVD), thermo-reactive deposition and thermal spray process are some of the widely used techniques for application of coatings to moulds that have shown promising results for increasing wear resistance, reducing die maintenance and machine down time [1-6]. Depending on the applied process, some of these coatings often fail due to high level of porosity and poor bonding of the applied surface to the base material. Laser aided direct metal deposition (DMD) can be used to enhance the property of the coating. DMD is a laser cladding process in which a particular part of the substrate can be coated with a material which has superior properties, producing a fusion bond between the two materials with minimal dilution of the clad by the substrate. Currently DMD is used to produce objects for tooling and mould production. The greatest potential of the DMD process is the capability of producing specialized and functional products such as bi-metallic structures through metallurgical bonding of the coating and substrate materials. Moreover, both similar and dissimilar materials can be coated using DMD, which holds major advantage over any other joining method for industrial applications.

In DMD process a laser beam is used to create a melt pool on the surface of a solid substrate into which a metallic powder is injected [7-9]. The laser melts the powder and fuses it on to the substrate creating a fully dense, metallurgically bonded bead. By overlapping the beads, usually by $50 \%$, a continuous layer is produced. However, the properties of the clad do not entirely depend upon the materials alone. Laser processing parameters and chemical composition of the materials have significant impact on the properties of the clad. Particularly, when the clad materials are different from the substrate, the process mechanics involved in fusing two different materials at the same energy from a laser beam is very complex. Though DMD can be applied for coating dissimilar metals through metallurgical bonding, this surface treatment is limited for copper, due to the high reflectivity of copper to laser beam during laser cladding and also due to high thermal conductivity of copper. Specifically, this condition of high thermal conduction and high reflective characteristic of copper to the infrared output wavelength of a $\mathrm{CO}_{2}(10.6 \mu \mathrm{m})$ laser results in lower process efficiency and make the process more complex. Therefore, it is almost certain that production of $\mathrm{H} 13$ tool steel clad on copper alloy substrate is entirely parameter responsive. To succeed in producing quality bi-metallic structure of steel on copper alloy substrate, DMD process parameters like laser power, laser spot size, scanning speed and powder mass flow rate need to be applied precisely. This can be done through investigation of the response of process parameters on clad. The potential benefit of investigating the process response is twofold. Firstly, understanding the build parameter effects on process response will aid development of further intelligent process control. Secondly, understanding the process response will allow users to select appropriate parameter values prior to processing in order to produce parts with desired physical properties.

Several studies have been carried out in laser cladding of various materials which mainly focused on selecting appropriate materials to be processed, developing the process and general process parameter selection $[10,11]$. Choi et al. [12] investigated the characteristics of steel deposited on steel substrate examining the performance of the DMD process with the material 
characteristics of hardness, porosity, microstructure, and composition. Emamian et al. [13, 14] investigated the effects of laser parameters on the quality of an in-situ formed $\mathrm{TiC}-\mathrm{Fe}$ based composite clad and found that they affect the bonding between clad/substrate and cooling rate. Wang et al. [15] reported the effect of laser power and heat treatment process on microstructure and property of multi-pass $\mathrm{Ni}$ based alloy laser cladding coating and reported that with the increase of laser power, corrosion resistance and microhardness has been greatly improved. Wang et al. [16] investigated the effects of crucial process parameters, such as laser power, scanning speed and wire delivery rate on the clad layer of direct laser deposition (DLD) using coaxial inside-beam wire feeding technique. Finite element analysis (FEA) has also been employed for metallurgical characterization and hardness measurements to quantify the effect of processing parameters on the variation of geometrical features (size and shape) of the clad, and the surface properties (hardness, resistance to heat, wear, and corrosion) [17]. Zhao et al. [18] investigated the influences of laser cladding parameters on nickel-based composite coatings on H13 steel surface to improve the wear resistance. Mahamood et al. [19] studied the influence of laser power and scan speed on microhardness of laser metal deposited titanium alloy on titanium alloy and found that as the laser power was increased, the microhardness was found to decrease and as the scanning speed was increased, the microhardness also increased. Shah et al. [20] carried out a parametric study of functionally graded $316 \mathrm{~L}$ stainless steel and Inconel718 thin wall structures made by laser direct metal deposition and reported that tensile strength of functionally graded material is dependent on the laser power and powder mass flow rate. DMD processed tungsten and Inconel 718 on high strength copper substrate are studied as well [21]. Although these works provide knowledge of various aspect of laser cladding process, some important factors such as reflectivity of copper, influence of process parameters in manufacturing 3D structure of steel on copper substrate have not been well understood. Therefore, specific study of the scientific and technical aspects of DMD of H13 tool steel on copper alloys is of great significance for fabrication of copper based bi-metallic dies for die casting and injection moulding industries [22, 23]. The innovation lies in the method of depositing a layer of high melting point partially soluble H13 tool steel powder onto a die made of low melting point solid copper alloy of high thermal conductivity. This will potentially lead to faster cooling, reduction in cycle time and increased die life. Such studies will involve characterizing the influence of the various process parameters on the deposition process, determining difficulty associated with 3D manufacturing of bimetallic structure of these two materials using DMD and finally selection of a suitable set of process parameters that overcome the associated difficulty for a sound and functional structure.

This paper investigates the influence of various process parameters such as laser power, laser spot size (focus size), scanning speed and powder mass flow rate on the deposition process of H13 tool steel on Copper alloy substrate. To find out the relationship between process parameters and cladding, various common characteristics in rapid prototyping, such as, distribution of porosity, microhardness and micro cracks in the layer have been investigated. Reflectivity, a common barrier associated with laser 
processing on copper with a $\mathrm{CO}_{2}$ laser was also considered during the deposition process. In fact a set of process parameters has been determined to overcome high reflection and to produce good quality clad.

\section{Experimental Work}

\section{Laser Cladding}

H13 tool steel was deposited on a copper alloy substrate using POM DMD 505 laser cladding facility. In this facility, the laser beam generates a melt pool on a substrate material while a second material in powder form from a feeder is injected into the melt pool with a concentric nozzle head, where a laser beam and powder come through the same nozzle. A continuous wave $\mathrm{CO} 2$ laser with a maximum power of $5 \mathrm{~kW}$ was used to produce beads and clads. Copper alloy plate was supplied by Bohler Uddeholm (Australia) Pty Ltd. Chemical compositions of copper alloy plate and H13 tool steel powder are listed in Tables 1 and 2. The process responses are usually the physical properties such as distribution of porosity, strength and degradation of deposited clad. These properties are all influenced by process parameters. Whole experimental work was conducted in three steps through analysis of various process responses.

\section{Preliminary Laser Cladding Trials}

Initially, for analysis purposes, bead, which is a single track produced in a single pass with one set of process parameters was constructed. With this research, the main intention was to select a set of parameters that are capable of sufficiently melting both materials to make a metallurgical bond. Therefore, in the early stage of the study, few trials were carried out by using a range of parameters. Table 3 shows summary of the combinations of parameters used in these trials. Figure 1 shows the corresponding steel beads produced on the copper substrate. After visual observation of the beads, one set of parameters with $3 \mathrm{~kW}$ laser power was selected to clad a $25 \times 25 \mathrm{~mm}$ square area (Fig. 1, area 1). Laser beam overlap was set at $50 \%$ and oxidation was avoided by using Argon gas shielding. Area 2 in Fig. 1 was deposited with the same process parameters but with tilted nozzle position. Reason for tilting nozzle has been explained in results and discussion section.

\section{Trials with Low Power Laser to Reduce Back Reflection}

In these set of experiments, the possibility to construct tool steel bead on copper alloy substrate using low power laser that would create bead without high reflection of the

Table 1 Chemical composition of copper alloy substrate

\begin{tabular}{llll}
\hline Element & $\mathrm{Co}+\mathrm{Ni}$ & $\mathrm{Be}$ & $\mathrm{Cu}$ \\
\hline Chemical composition & 0.5 & 1.9 & Balance \\
\hline
\end{tabular}


Table 2 Chemical composition of $\mathrm{H} 13$ tool steel

\begin{tabular}{llllllll}
\hline Element & $\mathrm{C}$ & $\mathrm{Mn}$ & $\mathrm{Si}$ & $\mathrm{V}$ & $\mathrm{Mo}$ & $\mathrm{Cr}$ & $\mathrm{Fe}$ \\
\hline Chemical composition & $0.35 \%$ & $0.4 \%$ & $1 \%$ & $1 \%$ & $1.5 \%$ & $5 \%$ & Balance \\
\hline
\end{tabular}

laser beam was investigated. Initially the powder delivery nozzle head (containing the co-axial laser beam) was kept tilted to minimize back reflections from the samples. The laser scanning speed (or travel speed of nozzle) was kept fixed at $150 \mathrm{~mm} / \mathrm{min}$, while powder mass flow rate was varied in the range of 1.58 to $4.6 \mathrm{~g} / \mathrm{min}$. In POM DMD505 system, the laser spot size is represented by focus size setting on the machine, which varies in the range of -20 to +20 , with -20 representing the smallest spot size (around $1 \mathrm{~mm}$ ) and +20 representing the largest spot size (around $2.2 \mathrm{~mm}$ ) depending upon the laser power used. In this study, the laser spot size setting was varied from -18 to +5 values. Two laser powers, $2 \mathrm{~kW}$ and $2.5 \mathrm{~kW}$ were used in these trials. Table 4 shows these parametric combinations and Fig. 2 shows the produced beads with these parametric combinations (numbered 1 to 13). At the end of this step, to investigate the nature of reflection during large area deposition with these parametric combinations, three pads were deposited. Two pads each $15 \times 15 \mathrm{~mm}$ were deposited with $2 \mathrm{~kW}$ and $2.5 \mathrm{~kW}$ laser power (Fig. 2, area 1 and 2), while in the next pad, the area was increased to $60 \times 25 \mathrm{~mm}$ and was deposited with $2 \mathrm{~kW}$ laser power in single operation (Fig. 2, area 3).

\section{Preparing Clad Pads}

For further analysis of clads, various pads of tool steel were deposited on copper substrate with different combinations of laser power (LP) and powder mass flow rate (PFR). The deposition area was $15 \times 10 \mathrm{~mm}$ for all these

Table 3 Summary of the preliminary trials

\begin{tabular}{llllll}
\hline Trial order & $\begin{array}{l}\text { Laser power } \\
(\mathrm{W})\end{array}$ & $\begin{array}{l}\text { Powder mass flow } \\
\text { rate }(\mathrm{g} / \mathrm{min})\end{array}$ & $\begin{array}{l}\text { Spot size } \\
\text { setting }\end{array}$ & $\begin{array}{l}\text { Scanning speed } \\
(\mathrm{mm} / \mathrm{min})\end{array}$ & Visual observation \\
\hline R1 & 1500 & 9.2 & +20 & 500 & No bonding \\
R2 & 2000 & 9.2 & +20 & 500 & No bonding \\
R3 & 2500 & 9.2 & +20 & 500 & No bonding \\
R4 & 4000 & 9.2 & +20 & 250 & Poor bonding \\
R5 & 5000 & 9.2 & +20 & 250 & Poor bonding \\
R6 & 5000 & 6.2 & 0 & 150 & Poor bonding \\
R7 & 5000 & 3.15 & -15 & 150 & Poor bonding \\
R8 & 5000 & 1.58 & -18 & 150 & Better than previous \\
R9 & 5000 & 0.8 & -18 & 150 & Good bonding \\
R10 & 4000 & 0.8 & -18 & 150 & Good bonding \\
R11 & 3000 & 0.8 & -18 & 150 & Good bonding
\end{tabular}




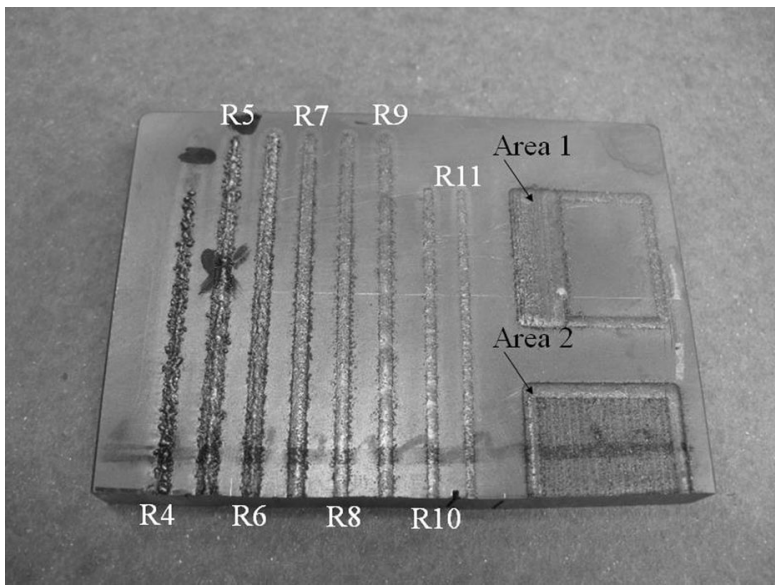

Fig. $1 \mathrm{H} 13$ beads and clads produced on copper substrate in preliminary trials

deposited clads. Scanning speed and laser spot size setting were kept constant at the values $150 \mathrm{~mm} / \mathrm{min}$ and +5 respectively throughout the deposition as high values of these two parameters, combined with other parametric combinations, were found to produce insufficient heat energy to melt the steel powder. Since, reflection was a major obstacle in laser processing of the copper alloy and the $3 \mathrm{~kW}$ laser power resulted in tremendous reflected heat from the copper substrate, some clads were built by using different laser powers sequentially. In

Table 4 Summary of the trials to reduce back reflection

\begin{tabular}{llllll}
\hline Trial order & $\begin{array}{l}\text { Laser power } \\
(\mathrm{W})\end{array}$ & $\begin{array}{l}\text { Powder mass flow } \\
\text { rate }(\mathrm{g} / \mathrm{min})\end{array}$ & $\begin{array}{l}\text { Spot size } \\
\text { setting }\end{array}$ & $\begin{array}{l}\text { Nozzle } \\
\text { angel }\left({ }^{\circ}\right)\end{array}$ & Visual observation \\
\hline L1 & 2000 & 4.6 & -18 & 20 & Very poor bonding \\
L2 & 2000 & 3.15 & -18 & 20 & Very poor bonding \\
L3 & 2000 & 1.58 & -18 & 20 & Poor bonding \\
L4 & 2000 & 1.58 & -15 & 20 & Poor bonding \\
L5 & 2000 & 1.58 & -13 & 20 & Poor bonding \\
L6 & 2000 & 1.58 & -10 & 20 & Poor bonding \\
L7 & 2000 & 1.58 & -5 & 20 & Good bonding \\
L8 & 2000 & 1.58 & +5 & 20 & Good bonding \\
L9 & 2500 & 2.3 & +5 & 20 & Good bonding \\
L10 & 2000 & 2.3 & +5 & 20 & Good bonding \\
L11 & 2000 & 2.3 & +5 & 10 & No reflection \\
L12 & 2000 & 2.3 & +5 & 5 & No reflection \\
L13 & 2500 & 2.3 & +5 & 0 & No reflection \\
\end{tabular}




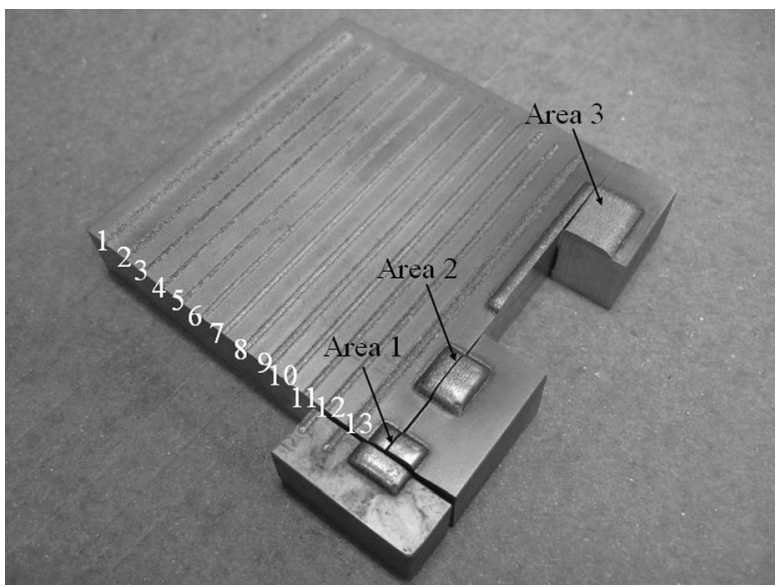

Fig. 2 H13 beads and clads produced on copper substrate with low power laser

these clads, first few layers were deposited using $2.5 \mathrm{~kW}$ laser power followed by clads deposited using high laser power $(3 \mathrm{~kW})$ at the top progressively. Table 5 summarizes these parametric combinations and Fig. 3 shows deposited layers.

\section{Metallurgical Analysis}

All samples were cut in the transverse direction and polished with fine diamond polishing machine up to $1 \mu \mathrm{m}$ for porosity analysis and hardness measurement. Afterwards, the parts were rinsed with alcohol and dried with air in order to remove any contaminations. Finally the parts were etched using $2 \%$ nital to allow a precise microstructural view of the surfaces. SEM images were obtained using SUPRA 40 VP SEM and Philips XL30 FEG SEM. The microhardness across the interface of the specimens was measured using CLARK Microhardness Tester (Model- CM 400AT) with $300 \mathrm{~g}$ load.

Table 5 Summery of the parametric combinations to deposit clad pads

\begin{tabular}{|c|c|c|c|}
\hline $\begin{array}{l}\text { Clad Pad No } \\
\text { (in Fig. 3) }\end{array}$ & $\begin{array}{l}\text { Laser } \\
\text { power } \\
(\mathrm{kW})\end{array}$ & $\begin{array}{l}\text { Powder } \\
\text { feed } \\
(\mathrm{g} / \mathrm{min})\end{array}$ & Remarks \\
\hline 1 & 2 & 1.58 & 6 layers all with same parameters \\
\hline 2 & 2.5 & 1.58 & 6 layers all with same parameters \\
\hline 3 & 2.75 & 2.3 & 6 layers all with same parameters \\
\hline 4 & & 2.3 & 2 layers with $2.5 \mathrm{~kW} \mathrm{LP}$ and 3 layers with $2.75 \mathrm{~kW} \mathrm{LP}$ \\
\hline 5 & 2.5 & & 2 layers with $2.3 \mathrm{gm} / \mathrm{min}$ PFR and 4 layers with $1.58 \mathrm{gm} / \mathrm{min}$ PFR \\
\hline 6 & & 2.3 & 6 layers each 2 with $2.5,2.75$ and $3 \mathrm{~kW}$ LP respectively \\
\hline
\end{tabular}




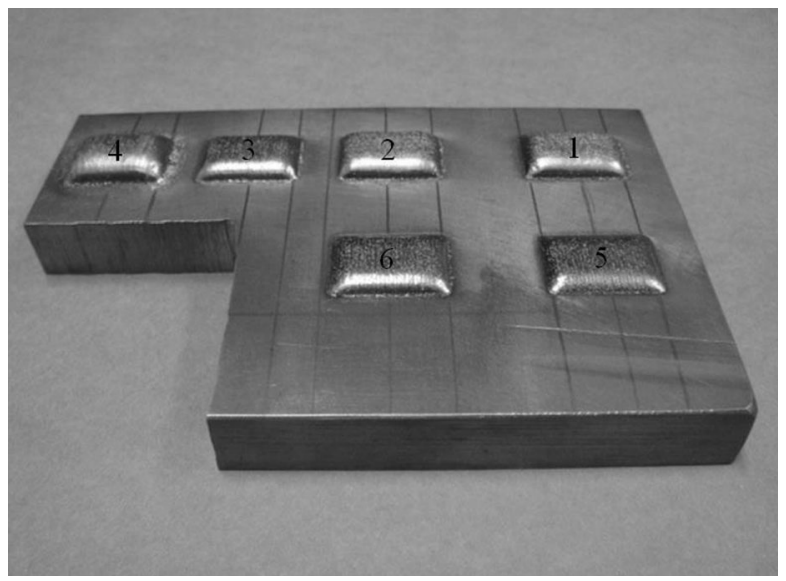

Fig. 3 H13 steel clad pads produced on copper substrate with various combinations of process parameters

\section{Results and Discussion}

\section{Preliminary Trials}

The first experiments considered tool steel beads on copper plate surface to determine a set of deposition parameters that are capable of sufficiently melting both the tool steel powder and copper substrate material. These experiments were performed using a broad range of processing parameters. Figure 1 shows the quality of bead formation observed visually with various laser processing parameters. In the preliminary trials, copper alloy was thought to be melted with low energy due to its low melting temperature. Therefore these trials were explored with low laser power starting from $1.5 \mathrm{~kW}$. But visual inspection of the beads revealed that, for each power setting no bead was produced up to $2.5 \mathrm{~kW}$ laser power with high values of powder mass flow rate $(9.2 \mathrm{~g} / \mathrm{min})$, scanning speed $(500 \mathrm{~mm} / \mathrm{min})$ and a larger spot size setting $(+20)$. It meant that the energy produced with the combination of these parameters was not able to create a melt pool on copper substrate. The high thermal conductivity of copper that transferred heat from the surface to the other part of the substrate made the melting further difficult. In an effort to create a melt pool on substrate, the laser power was gradually increased to $4 \mathrm{~kW}$ and $5 \mathrm{~kW}$ while scanning speed was decreased to $250 \mathrm{~mm} /$ min and $150 \mathrm{~mm} / \mathrm{min}$ to increase intensity of the energy delivered.

The first bead was produced at $4 \mathrm{~kW}$ laser power and $250 \mathrm{~mm} / \mathrm{min}$ scanning speed though bonding of the materials was poor (bead R4 in Fig. 1). The situation could not be rectified even at maximum $5 \mathrm{~kW}$ power with all other parameters remaining constant (bead R5 in Fig. 1). These beads clearly demonstrated insufficient melting as lots of powder particles were present in the beads, which were caused by excessive powder mass flow rate leading to insufficient melting of powder. Therefore, powder mass flow rate was gradually decreased to $6.2,3.15,1.58$ and $0.8 \mathrm{~g} / \mathrm{min}$ along with decreased spot size settings $(0,-15$ and -18$)$ and scanning speed $(150 \mathrm{~mm} / \mathrm{min})$ to increase the energy intensity while laser power was fixed at $5 \mathrm{~kW}$. These reductions vastly affected the deposition process since visual examination of these tracks revealed that in all cases a bead was produced and it was well bonded to the substrate. Bead R7 in Fig. 1 produced 
with laser power $5 \mathrm{~kW}$, powder mass flow rate $3.15 \mathrm{~g} / \mathrm{min}$, spot size setting of -15 and scanning speed $150 \mathrm{~mm} / \mathrm{min}$ looked sound for further deposition. Nevertheless, SEM image shown in Fig. 4 depicts the presence of numerous micro cracks in the bead. These micro cracks were well described by Simchi [24] who found that, at high laser energy input, delamination of sintered layers and formation of large cracks were feasible. The image also shows insufficient melting due to the large powder mass flow rate.

The tool steel bead quality improved with the reduction of powder mass flow rate while all other parameters were fixed. Figure 5 illustrates that the powder was better melted and bonded to the copper substrate in the bead produced with $1.58 \mathrm{~g} / \mathrm{min}$ powder mass flow rate. However, porous holes were present in the microstructure which reduced with the reduction of powder mass flow rate with all other parameters fixed (Fig. 6). Fig. 7 shows a comparison of porosity area fractions in the beads. Simchi [24] showed that at high laser intensity, delamination of laser processed layer occurs due to thermal stresses, formation of gas pores occurs during solidification, porosity formation occurs due to material shrinkage and balling effects. Therefore, in the next trials laser power was reduced gradually keeping all other parameters fixed. Thus, the bead produced with $4 \mathrm{~kW}$ laser power showed reduced porous holes and beads produced with $3 \mathrm{~kW}$ laser power showed almost pore free microstructure as shown in Figs. 8 and 9 respectively. Though the microstructure showed low level of porosity, this set of parameters with $3 \mathrm{~kW}$ laser power was not suitable for large area deposition (Fig. 1, area 1) as in this case, back reflection from the substrate was incident on the nozzle and burnt it (Fig. 10).

Making copper substrate surface rough, tilting nozzle head and reduction of laser power could be three effective ways to minimize the back reflection. In this experiment sand blasting at the copper alloy substrate was performed, but it did not eliminate back reflection completely. The degree of roughness is restricted since highly rough surfaces cause potential defects at the interface of clad and substrate [25, 26]. Again, at the tilted position of the nozzle, reflection was high enough to melt nozzle back plate and feedback tube of the machine (Fig. 11) during large area deposition (Fig. 1, area 2). Tilting nozzle further could potentially damage some other part as tilting the nozzle was

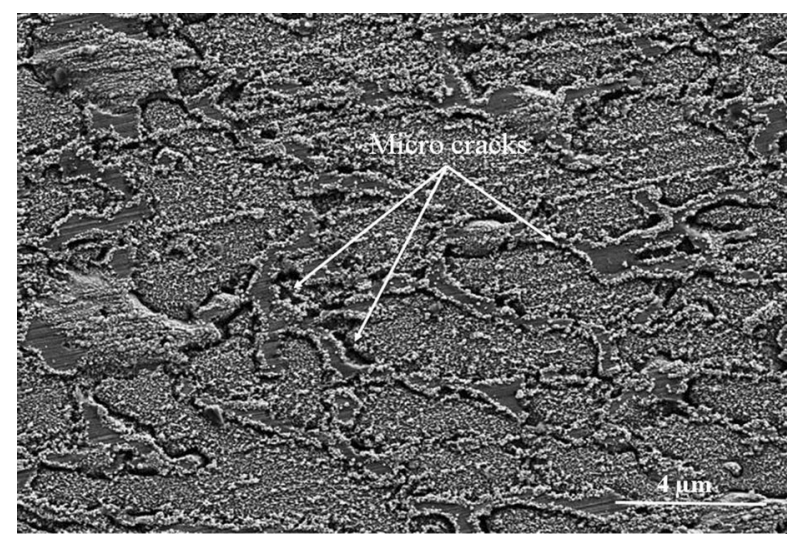

Fig. 4 SEM image of micro cracks of the steel bead produced with laser power $5 \mathrm{~kW}$, powder mass flow rate $3.15 \mathrm{~g} / \mathrm{min}$, laser spot setting -15 and feed rate $150 \mathrm{~mm} / \mathrm{min}$ 


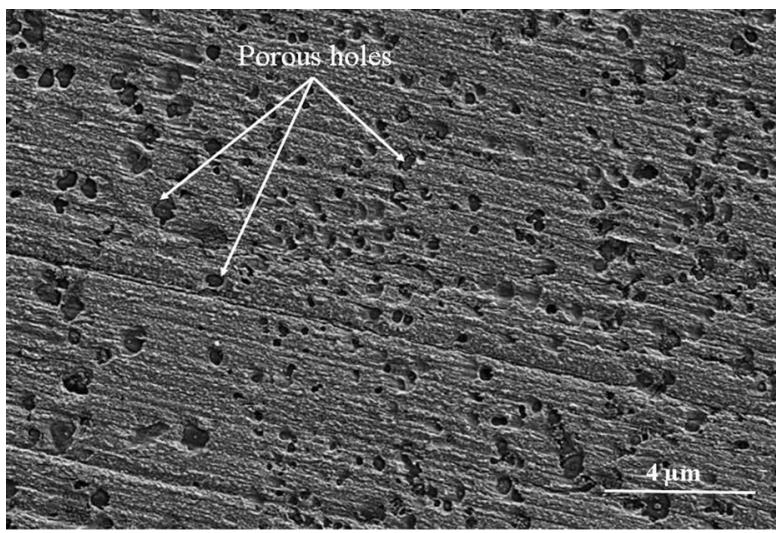

Fig. 5 SEM image of the steel bead with porous holes produced with laser power $5 \mathrm{~kW}$, powder mass flow rate $1.58 \mathrm{~g} / \mathrm{min}$, laser spot setting -18 and feed rate $150 \mathrm{~mm} / \mathrm{min}$

not actually reducing reflection rather directed reflected light to other machine parts instead of nozzle tip. Moreover, while reading the CAD model for 3D deposition of complex shaped products, DMD machine does not operate from the tilting position since it creates own tool path from the vertical position of the nozzle relative to the copper substrate. As a result, the laser power was needed to be reduced further to avoid these consequences.

\section{Low Power Laser Trials}

The aim of reducing laser power was to minimize beam reflection while producing quality tool steel clad layers. Initially, laser power was reduced to $2 \mathrm{~kW}$ in these trials. The nozzle head was kept tilted from the beginning to avoid any unexpected melting of nozzle tip from the reflected laser beam that might be produced. Keeping in mind that if more powder was used it could absorb most of the energy from the laser beam leaving less energy to be reflected, powder mass flow rate was also increased at the beginning of these trials. But, reduction of laser power in combination with increased powder

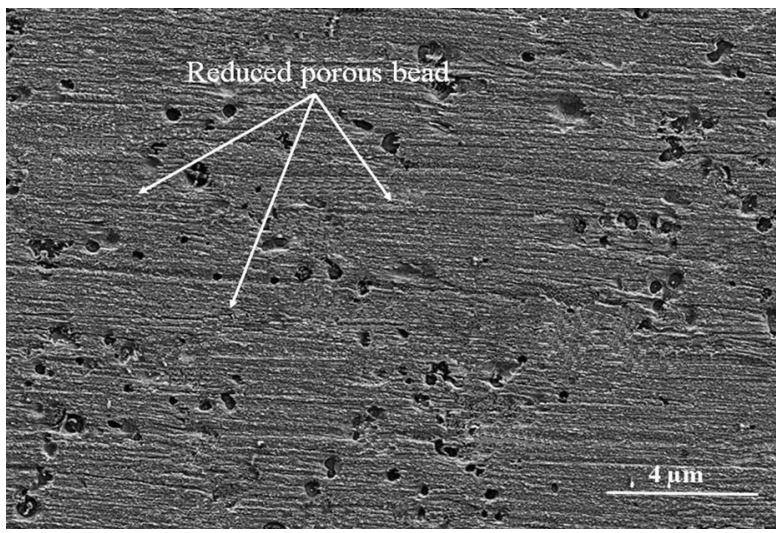

Fig. 6 SEM image of the steel bead with reduced porosity produced with laser power $5 \mathrm{~kW}$, powder mass flow rate $0.8 \mathrm{~g} / \mathrm{min}$, laser spot setting -18 and feed rate $150 \mathrm{~mm} / \mathrm{min}$ 


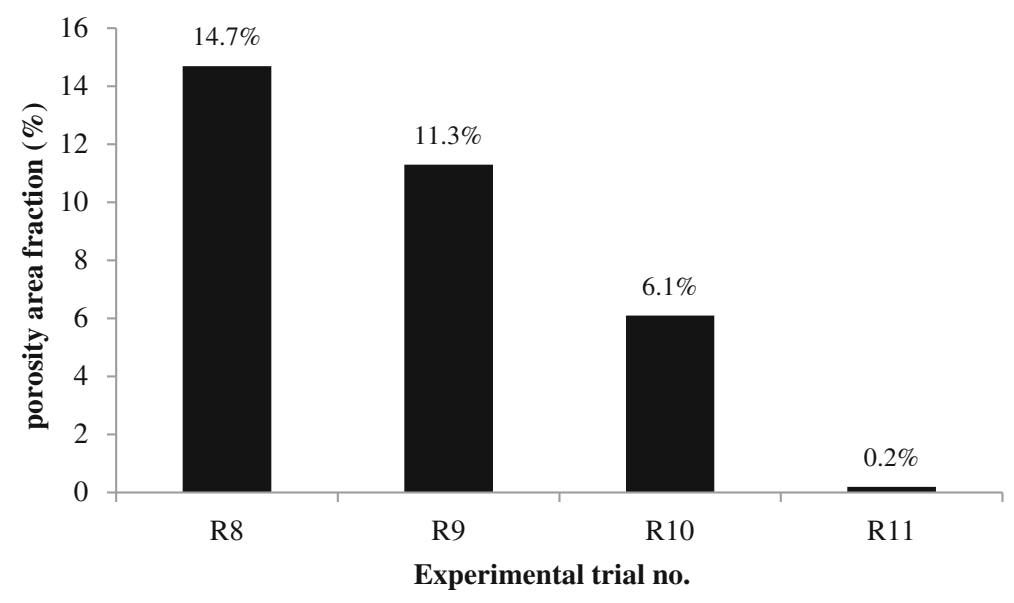

Fig. 7 Quantitative analysis of porous area in DMD produced H13 steel beads on copper substrate

mass flow rate resulted in insufficient melting since the bead produced with $2 \mathrm{~kW}$ laser power and $4.6 \mathrm{~g} / \mathrm{min}$ powder flow rate showed very poor bonding (Fig. 2, bead 1). It happened due to the fact that low energy of the laser beam could not provide sufficient heat for the large amount of powder to be molten to create adequate bonding. Though bead quality improved gradually with reduction of powder mass flow rate, the bonding was not adequate even up to $1.58 \mathrm{~g} / \mathrm{min}$ powder mass flow rate. Therefore, another process parameter i.e., laser spot size was considered to be altered to change the energy density. This change in the process parameter influenced the bead quality immediately since the bonding improved considerably with the decrease of spot size (Fig. 2, beads 4-7). Bonding looked much better when spot size setting was changed from negative $(-5)$ to positive $(+5)$ value with the same set of process parameters (Fig. 2, bead 8). Even increasing powder mass flow rate slightly from $1.58 \mathrm{~g} / \mathrm{min}$ to $2.3 \mathrm{~g} / \mathrm{min}$ with this set of process parameters showed the same quality bonding as the bead produced with

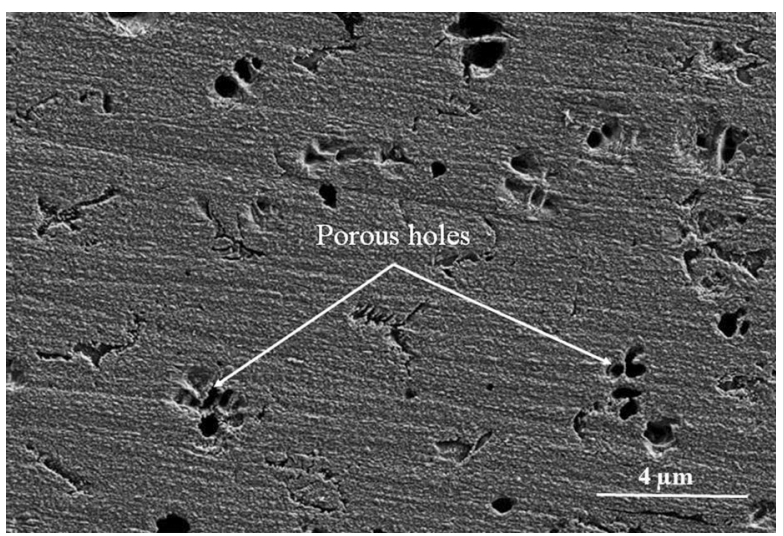

Fig. 8 SEM image of the steel bead produced with laser power $4 \mathrm{~kW}$, powder mass flow rate $0.8 \mathrm{~g} / \mathrm{min}$, laser spot setting -18 and feed rate $150 \mathrm{~mm} / \mathrm{min}$ 


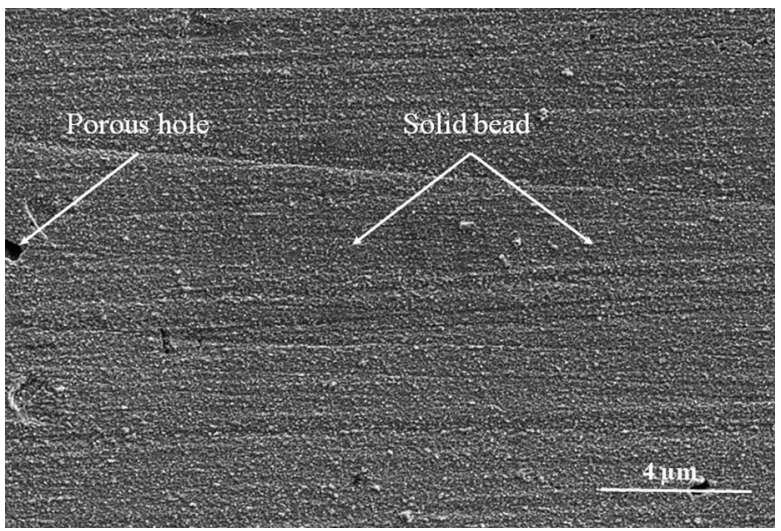

Fig. 9 SEM image of the steel bead produced with laser power $3 \mathrm{~kW}$, powder mass flow rate $0.8 \mathrm{~g} / \mathrm{min}$, laser spot setting -18 and feed rate $150 \mathrm{~mm} / \mathrm{min}$

$1.58 \mathrm{~g} / \mathrm{min}$ (Fig. 2, bead 10). In addition, one bead was successfully produced by increasing laser power to $2.5 \mathrm{~kW}$. However, it was not considered for large area deposition since this power could be unfavourable in terms of reflection. As a result, $2 \mathrm{~kW}$ laser power was considered for further deposition and nozzle head was shifted to vertical position gradually producing beads with good bonding and without reflection that could damage nozzle tip (Fig. 2, beads 11-13). Successful deposition of two pads of $10 \times 10 \mathrm{~mm}$ and $60 \times 25 \mathrm{~mm}$ without any reflected beam issues (Fig. 2, area 1 and 3) showed further possibility of using this set of process parameters. However, Fig. 12 shows that hardness was slightly above $200 \mathrm{HV}$ through the entire clad layers which was too low to be applied in high pressure and temperature applications. The reason for low hardness values was the incomplete melting of the tool steel powder. Though the clad looked well bonded from outside, the microscopic observation revealed that there were lots of particles in the surface that did not melt sufficiently to create fully dense clad (Fig. 13). In contrast, the hardness was high in $10 \times 10 \mathrm{~mm}$ pad (Fig. 2, area 2) deposited using $2.5 \mathrm{~kW}$ laser power, $2.3 \mathrm{~g} / \mathrm{min}$ powder mass flow rate and spot size setting of +5 (Fig. 14). The difference in hardness in clads with different laser power

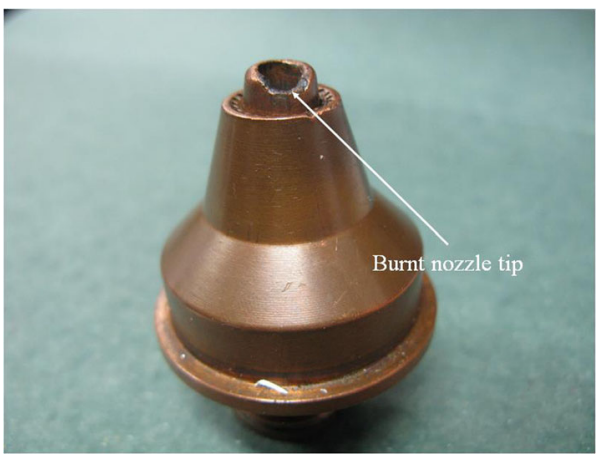

Fig. 10 Melted DMD nozzle due to back reflected light when using $3 \mathrm{~kW}$ laser powe 

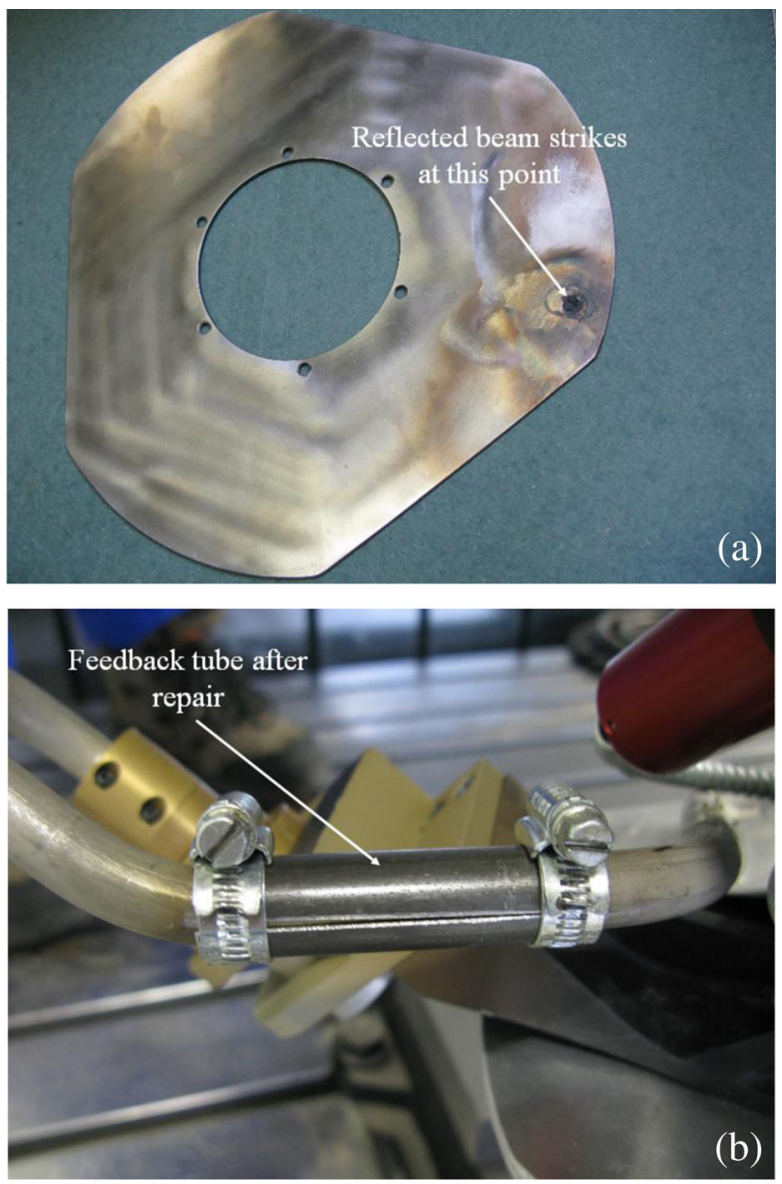

Fig. 11 Melting during large area deposition with $3 \mathrm{~kW}$ laser power and tilted DMD nozzle a back plate and b feedback tube

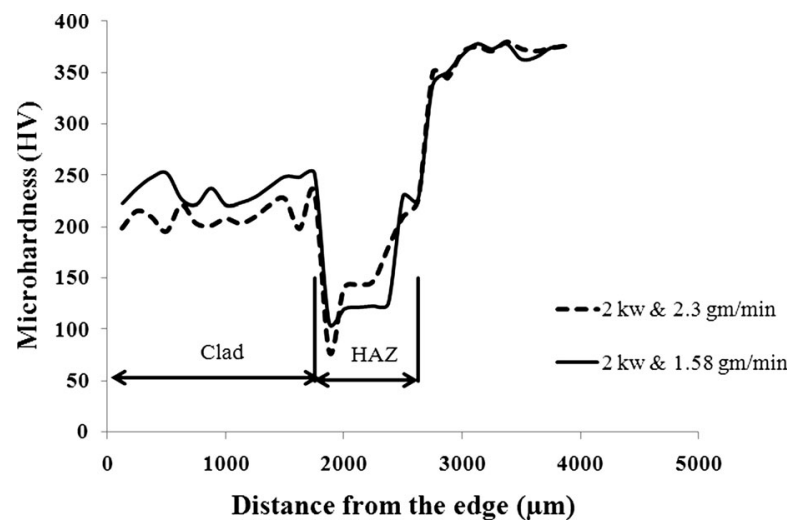

Fig. 12 Vickers microhardness (HV0.3) of steel clad deposited on copper substrate with $2 \mathrm{~kW}$ laser power for area 1 and area 3 of Fig. 2 


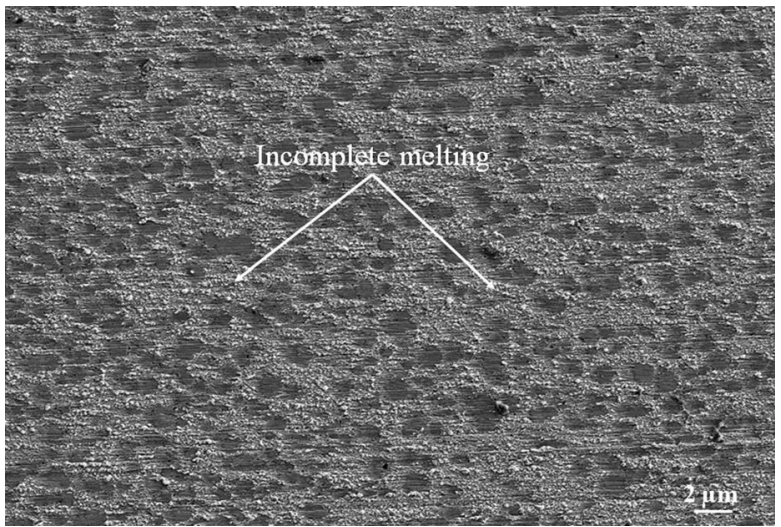

Fig. 13 SEM image of the steel clad with $2 \mathrm{~kW}$ laser power and $2.3 \mathrm{~g} /$ min powder mass flow rate showing incomplete melting of steel powder

urged analysis of hardness of various pads prepared with various combination of laser power.

\section{Analysis of Microhardness}

Through microhardness analysis of the pads, the main intention was to achieve a set of process parameters that was capable of producing sufficiently strong clads without reflection. Therefore, microhardness of clads were correlated with laser power and powder mass flow rate. Figure 12 showed that hardness increased slightly with decrease of powder mass flow rate though it was still not enough to be applied in high strength applications. Reduced powder mass flow rate facilitated more energy to be absorbed by fewer amounts of powder particles from molten pool of the copper substrate during cladding process and increased melting quality. In the same manner, increased laser power provided more energy in molten pool for powder to be melted completely which resulted in increased hardness of the clad. Figure 14 showed that

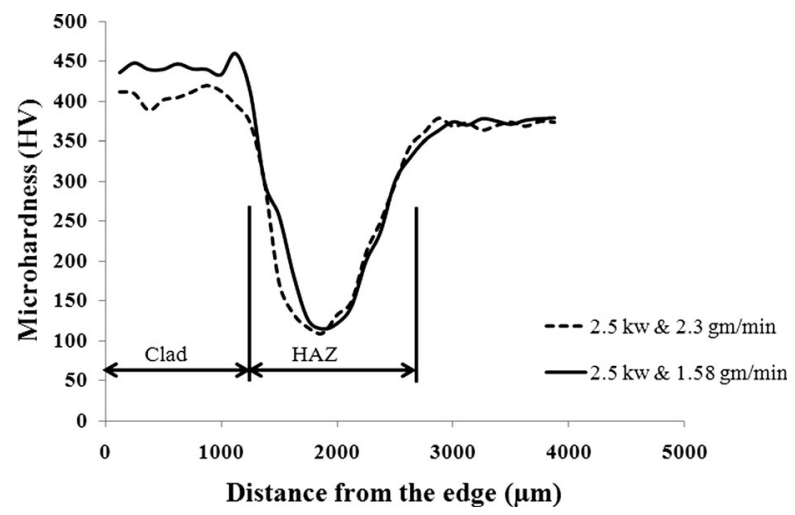

Fig. 14 Vickers microhardness (HV0.3) of steel clad deposited on copper substrate with $2.5 \mathrm{~kW}$ laser power for area 2 of Fig. 2 
microhardness was around $410 \mathrm{HV}$ in the clad deposited with $2.5 \mathrm{~kW}$ laser power and $2.3 \mathrm{~g} / \mathrm{min}$ powder mass flow rate. Though reduction of powder mass flow rate offered hardness close to $450 \mathrm{HV}$, this combination of parameters was not applicable as it was found reflecting heat to damage the nozzle tip of DMD machine. At high laser power like $2.5 \mathrm{~kW}$ with reduced powder mass flow rate $(1.58 \mathrm{~g} / \mathrm{min})$, the heat energy in the molten pool could not be absorbed fully by the fewer amount of powder particles and hence remaining amount of energy was reflected from the substrate. The $2.75 \mathrm{~kW}$ laser power was also reflecting heat even with $2.3 \mathrm{~g} / \mathrm{min}$ powder mass flow rate due to the same reason. Figure 15 shows microhardness of tool steel clad deposited with $2.75 \mathrm{~kW}$ laser power. Though a small pad of $15 \times 10 \mathrm{~mm}$ could be deposited and hardness of this clad was higher compared to other pads, $2.75 \mathrm{~kW}$ laser power was also not found to be suitable for large area deposition since it could potentially damage machine by reflected beam. The increase in hardness with increase in laser power however offered a method to combine different level of laser powers to clad different layers of steel on copper alloy substrate. This method could rectify process shortcoming associated with reflection as well as provide sufficient strength of the clad. In this method, first two layers were deposited with $2.5 \mathrm{~kW}$ laser power without reflection and then on top of this layer further cladding was done. This way, the first layer produced with $2.5 \mathrm{~kW}$ may not provide sufficient strength and melting of the powder. However, it worked as substrate for the next layers, which helped this layer to melt completely during deposition of next layers with higher laser power to offer increased hardness. Figure 16 demonstrates hardness of the clad found in this method. It showed that hardness was around $480 \mathrm{HV}$ from the top to around $1.5 \mathrm{~mm}$ in the layer. The hardness then dropped below $450 \mathrm{HV}$ in the region that was deposited with $2.5 \mathrm{~kW}$ laser power. SEM image in Fig. 17a shows complete melting of steel powder particles. Unlike layers produced with low laser power, proper melting of the powder particles in the layers with high power laser left no porous holes in the clad that could affect strength of the clad. The hardness reduced largely in heat affected zone (HAZ) of the copper substrate, just below the interface up to around $1 \mathrm{~mm}$ in the copper substrate plates in all specimens. Heat affected zone (HAZ) is a common feature in laser cladding which changes the grain size of the substrate material to change material properties. Applied laser caused grain

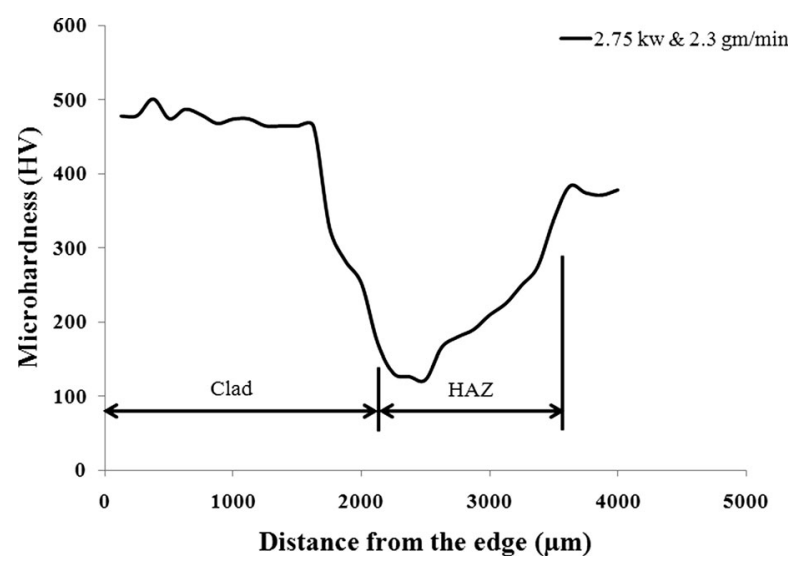

Fig. 15 Vickers microhardness (HV0.3) of steel clad deposited on copper substrate with $2.5 \mathrm{~kW}$ laser power 


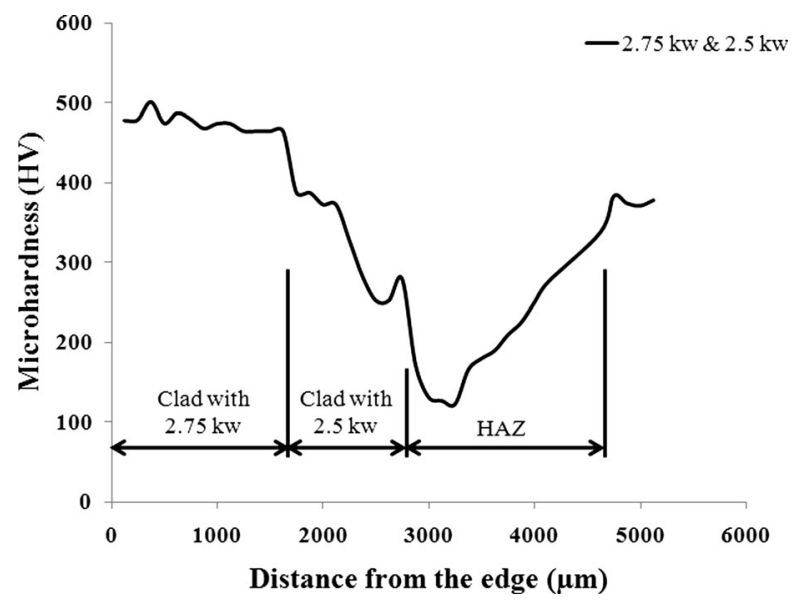

Fig. 16 Vickers microhardness (HV0.3) of steel clad on copper substrate deposited with $2.75 \mathrm{~kW}$ and $2.5 \mathrm{~kW}$ laser power
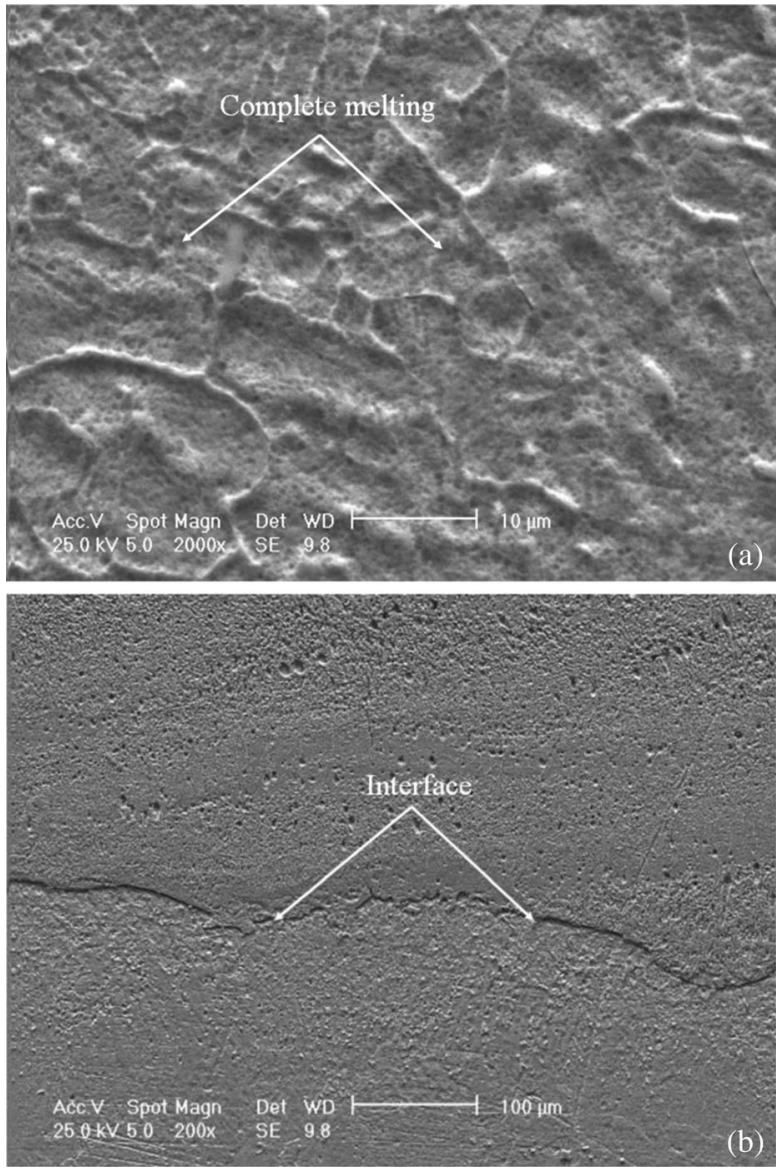

Fig. 17 SEM image of the steel cladding with the combination of 2.5 and $2.75 \mathrm{~kW}$ laser power a fully melted layer without porous holes $\mathbf{b}$ interface between steel clad and copper substrate 
coarsening of copper alloy substrate plate to reduce hardness. The fully melted interface of the cladding shown in Fig. $17 \mathrm{~b}$ proved the further applicability of this method.

\section{Dilution of Copper in Steel}

The phenomenon of dilution of copper in the cladded layer of tool steel by the DMD process has been investigated in a previous study by the authors [27] by considering deposited H13 steel samples of various thicknesses ranging from 0.6 to $2.1 \mathrm{~mm}$ on copper substrate. In that study, the scanning electron microscopy images of cross section of the cladded layer revealed the presence of copper as rounded particle surrounded by tool steel. The sample with $0.6 \mathrm{~mm}$ thickness showed large copper particles entrapped in steel. The size of the particles reduced with the increase of thickness distributing them as fine particles through the entire surface. The reason behind this is that in the DMD process, cladding is done layer by layer, where thickness of each layer depends on the process parameters. In this investigation, the steel was deposited with $0.3 \mathrm{~mm}$ thickness of each layer. In the first layer, more copper came in contact with molten steel and mixed in a large scale. But as the cladding went on, the copper content decreased, as shown by Energy Dispersive Spectroscopy (EDS), which quantifies the contents at the top surfaces of 0.6 and $2.1 \mathrm{~mm}$ thick samples [27]. Table 6 shows the quantitative analysis of EDS result, which confirms that the copper at the top of $0.6 \mathrm{~mm}$ thick sample is much higher and it is reduced to very small percentage at the top of $2.1 \mathrm{~mm}$ thick sample. As a result of this continuous reduction of copper, while depositing consecutive layer, copper particles of the previous layer melts down and are distributed as fine particles in the next layer.

\section{Conclusion}

Direct metal deposition of high strength tool steel on copper alloy substrate has a great potential in development of a highly efficient bi-metallic dies and tooling for industrial casting processes. Though high intensity of energy is required for DMD deposition of steel on copper substrate due to the higher thermal conductivity of copper alloys, this investigation has shown that laser power more than $2.5 \mathrm{~kW}$ is not suitable as it reflects tremendous heat to cause damage to the machine. In contrast, laser power less than $2.5 \mathrm{~kW}$ produces clads with low hardness. Therefore, $2.5 \mathrm{~kW}$ laser power is recommended for this particular application. Results also suggest that laser scanning speed should be applied within $150 \mathrm{~mm} / \mathrm{min}$ since scanning speed more than $150 \mathrm{~mm} / \mathrm{min}$ cannot produce sufficient intensity of heat to create a complete melt pool on the substrate. The powder mass flow rate should be within the range of $1.58-2.3 \mathrm{~g} / \mathrm{min}$ for any combination of the parameters. Investigations indicate that increase in laser power will lead to increase in the hardness. Nevertheless, more than $2.5 \mathrm{~kW}$ laser

Table 6 Quantitative analysis of $\mathrm{Cu}$ presence [27]

\begin{tabular}{llllr}
\hline Sample thickness (mm) & 0.6 & 0.9 & 1.5 & 2.1 \\
Cu content (\% wt) & 5.91 & 3.08 & 1.24 & 0.6 \\
\hline
\end{tabular}


power can't be used directly on copper alloy substrate due to reflection of laser beam. Therefore, to achieve high strength property of the clad, the first layer should be deposited with $2.5 \mathrm{~kW}$ laser power and on the top of first layer further depositions can be made with high power laser. Results also show that for all clads on copper alloy, hardness decreases significantly in heat affected zone (HAZ) due to grain coarsening. Dilution of copper particles in the cladded steel layer tends to be very small, of the order of $0.6 \%$ or less, for sample thickness $2.1 \mathrm{~mm}$ or more.

Acknowledgments Authors would like to acknowledge the technical support provided by Mr Girish Thipperudrappa in conducting DMD experiments at Swinburne University of Technology.

\section{References}

1. Gopal, S., Lakare, A., Shivpuri, R.: Evaluation of thin film coatings for erosive-corrosive wear prevention in die casting dies. Surf. Eng. 15(4), 297-300 (1999)

2. Rosso, M.: Performance enhancements of die casting tools trough PVD nanocoatings. Int. J. Mater. Form. 1(1), 1259-1262 (2008)

3. Nose, M.: Development of PVD - TiAlN/a-C nanocomposite coating for pressure die casting applications. Plasma Process. Polym. 4(1), S681-S686 (2007)

4. Ugues, D.: Study of the resistance to washout of PVD coated hot working tool steels. Int. J. Microstruct. Mater. Prop. 2(1), 99-108 (2007)

5. Inoue K, Honda F, Inoue KI: Development of advanced multi-layer PVD coating for aluminum diecasting metal molds. ICPMT2006 - Prog Mach Tech - Proc 8th Int Conf Prog Mach Tech, 241-244 (2006)

6. Lin JL, Salas O, Scarrera P, Brennan J, Mishra B: Degradation mechanisms of die coatings used in aluminum pressure die casting. Surf Eng Mat Sci III - Proceedings of a Symposium sponsored by the Surface Engineering Committee of the (MPMD) of the Minerals, Metals and Materials Society, (TMS), 163-175 (2005)

7. Mazumder J: Past present and future of art to part by Direct Metal Deposition. Proc $1^{\text {st }}$ Paci Int Con App Las Opt (PICALO) (2004)

8. Brandt, M., Scott, D.A., Emms, S.B., Yellup, J.M.: Laser cladding with a pulse Nd: YAG laser and optical fibers. J. Laser Appl. 9(2), 67-75 (1997)

9. Mazumder, J.: The direct metal deposition of H13 tool steel for 3-D components. JOM 49(5), 55-60 (1997)

10. Williams, J.D., Deckard, C.R.: Advances in modeling the effects of selected parameters on the SLS process. Rapid Prototyp. J. 4(2), 90-100 (1998)

11. Kruth, J.P., Wang, X., Laoui, T., Froyen, L.: Lasers and materials in selective laser sintering. Assem. Autom. 23(4), 357-371 (2003)

12. Choi, J., Chang, Y.: Characteristics of laser aided direct metal/material deposition process for tool steel. Int. J. Mach. Tools Manuf. 45(4-5), 597-607 (2005)

13. Emamian, A., Corbin, S.F., Khajepour, A.: Effect of laser cladding process parameters on clad quality and in-situ formed microstructure of Fe-TiC composite coatings. Surf. Coat. Technol. 205(7), 2007-2015 (2010)

14. Emamian, A., Corbin, S.F.: Khajepour: A Study on Laser Parameters Effect on Morphology of in-Situ FeTiC Particles Deposition on Mild Steel Using Laser Cladding Process. Proceedings of ICALEO, Anaheim (2010)

15. Wang C, Liu H, Zhang X, Zeng W, Jiang Y, Zhou R: Effect of laser power and heat treatment process on microstructure and property of multi-pass Ni based alloy laser cladding coating. Proc SPIE 2010 - Int Soc Opt Eng 7843, art no 78430Y (2010)

16. Wang, Y.K., Shi, S., Fu, G., Li, C.S.: Research on the key process parameters in direct laser deposition using coaxial inside-beam wire feeding. Appl. Mech. Mater. 43, 401-404 (2011)

17. Santhanakrishnan S, Kong F, Kovacevic R: Process parameters analysis of high power direct diode laser cladding. 29th Int Con App Las Electro-Optics (ICALEO)- Congress Proceedings. 103, 398-407 (2010) 
18. Zhao, L., Sun, R., Lei, Y.: Study of nickel-based composite coatings on H13 steel surface by laser cladding. Adv. Mater. Res. 154-155, 407-411 (2010)

19. Mahamood, R.M., Akinlabi, E.T., Akinlabi, S.: Laser power and scanning speed influence on the mechanical property of laser deposited titanium-alloy. Lasers Manuf. Mater. Process. 2, 43-55 (2015)

20. Shah, K., Haq, I.U., Khan, A., et al.: Parametric study of development of inconel-steel functionally graded materials by laser direct metal deposition. Mater. Des. 54, 531-538 (2014)

21. Mohammed J, Alexander SM: Defining coating material for Aluminum die casting molds using a laser cladding process. ICALEO Congress Proceedings, paper-203, 86-90 (2006)

22. Imran, M.K., Masood, S.H., Brandt, M.: Bimetallic dies with direct metal deposited steel on moldmax for high pressure die casting application. Int. J. Adv. Manuf. Technol. 52, 855-963 (2011)

23. Imran, M.K., Masood, S., Brandt, M., Bhattacharya, S., Gulizia, S., Jahedi, M., Muzumder, J.: Thermal fatigue behaviour of direct metal deposited H13 tool steel coating on copper alloy substrate. Surf. Coat. Technol. 206, 2572-2580 (2012)

24. Simchi, A.: Direct laser sintering of metal powders: Mechanism, kinetics and microstructural features. Mater. Sci. Eng. A 428, 148-158 (2006)

25. Mazumder, J., Schifferer, A., Choi, J.: Direct materials deposition: Designed macro and microstructure. Mater. Res. Innov. 3(3), 118-131 (1999)

26. Choi J, Mazumder J: Rapid manufacturing by laser aided direct metal deposition process: issues and examples. Proceedings of DETC'01, ASME, Pittsburg, PA, 2001, DETC2001/DAC-21043 (2001)

27. Imran, M.K., Masood, S.H., Brandt, M.: Microstructural investigation of direct metal deposition of H13 steel on high strength copper substrate. Proceedings of World Congress on Engineering, London, UK 1, 704-808 (2009) 